\title{
A Comparison of Knowledge and Experience of Autism Spectrum Disorder Among Teachers in the United Kingdom and China
}

\begin{abstract}
Teacher knowledge of Autism Spectrum Disorder (ASD) plays a key role in the successful inclusion of children with the disorder in public schools. It therefore becomes important to understand what impacts upon teachers' knowledge of ASD. As such, we aimed to investigate the role of experience and culture on teachers' knowledge of ASD. Public teachers working in the United Kingdom (UK; $n=51)$ and People's Republic of China $(n=$ 59) completed questionnaires measuring experience of teaching children with ASD and levels of knowledge about the disorder. Analysis was then conducted to examine how knowledge of ASD differed as a function of culture and experience. Results showed that teachers who had experience of working with children with ASD demonstrated a higher level of knowledge relating to the disorder. Further, teachers in the UK had significantly more knowledge of ASD than teachers in China. The results suggest cross-cultural differences in teachers' understanding of ASD. Training opportunities which allow teachers to work with children with ASD should be provided in both the UK and in China.
\end{abstract}

Keywords: Autism, Knowledge, China, UK, ASD, Education 


\section{Introduction}

Autism Spectrum Disorder (ASD) is a neurodevelopmental disorder characterized by problems with social communication and restricted or repetitive behaviours (American Psychiatric Association, 2013). Individuals with ASD have difficulty integrating, processing and communicating information. While some individuals with ASD will develop rich vocabularies, others have limited speech and communication skills (Wong et al., 2015). This means that for some with ASD, the initiation and maintenance of social relationships is challenging. Further, such individuals may be avoidant of new environments instead preferring familiar and routine surroundings (American Psychiatric Association, 2013; Duncan \& Grofer Klinger, 2010; Rotheram-Fuller, Kasari, Chamberlain, \& Locke, 2010). Those with ASD can achieve a good quality of life meaning that they will engage in a broad range of human activities and experiences which relate positively to overall wellbeing (Revicki et al., 2000). Despite this, for others, the disability can significantly impact independence (Burgess \& Gutstein, 2007; Farley et al., 2009), leaving some individuals with ASD requiring sheltered care for all of their adult lives (Smith, Maenner, \& Seltzer, 2012). As such, it becomes important to recognise the role of education in helping individuals with ASD learn important academic, socialization, communication and life skills.

The impact of education on the lives of children with disabilities is recognised by policy makers. Legislation now requires that children with physical, intellectual and behavioural disabilities are educated within UK public schools (e.g. United Nations Convention on the Rights of the Child. 1989, 2006; UNESCO Salamanca Statement, 1994, 2005; No Child Left Behind Act, 2001; Convention on the Rights of Persons with Disabilities, 2006, 2014). Such legislation was intended to increase the acceptance and participation of children with disabilities in public schools and thus provide equal educational opportunities (Brownell, 
Sinedelar, Kiely, \& Danielson, 2010; Lindsay, 2007). Despite this, many with ASD encounter negative experiences within a public school setting such as social isolation and bullying (Carrington \& Graham, 2001; Humphrey \& Lewis, 2008; Rowley et al., 2012). Further, in a review of 1300 special education studies, no clear support of the positive effects of inclusion on academic performance was obtained (Lindsay, 2007). As a result, it is important to consider what impacts upon the effectiveness of inclusion.

Classroom teachers' behaviour and attitudes play a role in determining the success of inclusion (De Boer, Pijl \& Minnaert, 2011; Subban \& Sharma, 2005; Wilson, Woolfson, Durkin, \& Elliott, 2016). For example, teachers must adjust behaviours to better accommodate children of all abilities. Curricular, resource, and instructional adaptations are required to make a difference to students and their learning (Avramidis \& Norwich, 2002; De Boer et al., 2011). Further, when a teacher responds to a child with ASD in a way which suggests the student is different, the typically developing children react by also treating the child differently (Bunch \& Valeo, 2004; Ford, 2013). However, the severity and complexity of symptoms often causes the inclusion of children with ASD to be difficult (Simpson, Boer-Ott, \& Smith-Myles 2003). In order to ensure teachers are able to make appropriate classroom adaptions for children with ASD, they must therefore have appropriate knowledge and training. For example, Leblanc, Richardson and Burns (2009) found that teachers with more knowledge about ASD had more positive perceptions about working with children with the disability. As such, inclusive practice may be improved by increasing knowledge and awareness of ASD among school staff. Although senior management have reported feeling able to work with children with ASD (Humphrey \& Symes, 2013, it is less clear as to whether teachers have sufficient knowledge regarding ASD (Barned, Knapp, \& Neuharth-Pritchett, 2011; Finch, Watson, MacGregor, \& Precise, 2013) and whether knowledge differs between cultures. 
Evidence suggests that teachers' knowledge of ASD may vary between Eastern and Western cultures. For example, Barnard, Broach, Potter and Prior (2002) found that among 6804 public and special school teachers in UK schools, only 19\% had received ASD-specific training. This figure, however, had increased to 66\% by 2012 (National Foundation for Education Research, 2012). This suggests that UK-based teachers are increasingly provided with ASD training. In contrast with the UK, inclusion policy is not mandatory in China (Liu, et al., 2016; Pang \& Richey 2006). Statistics indicate that $36 \%$ of school age children with disabilities were not receiving educational services within the People's Republic of China (China Disabled Persons' Federation, Beijing University, \& National Bureau of Statistics of China 2009). Further, McCabe, Wu and Zhang (2005) argued that children with ASD have been refused school enrollment because the school in do not understand or have the ability to work with children with ASD.

Despite increased knowledge of ASD seen within some key service providers (e.g. hospitals, health authorities, research institutes) across China (Sun et al., 2013), there still remains a lack of ASD awareness in most Chinese professions (Wang et al., 2012). Evidence suggests that teachers in China show poor knowledge of ASD development and symptoms. For example, Liu et al. (2016) found that in a sample of 471 China-based teachers, $83 \%$ provided inaccurate responses to over half of the questionnaire items assessing knowledge of ASD. On the other hand, Humphrey and Symes (2013) reported more optimistic findings in relation to teachers' knowledge of ASD in the UK. These findings suggest that knowledge of ASD may vary significantly between teachers working in UK-based schools and those working within China's education system. Despite this, no study has directly compared teacher knowledge of ASD among a sample of UK and Chinese schools. 
Such differences in knowledge between teachers in the UK and China may be a result of cultural differences (Norbury \& Sparks, 2013). Culture has a direct impact on the formation of social norms and plays a role in shaping our understanding of developmental disabilities (Ennis-Cole, Durodoye \& Harris, 2013; Myers, Abell, Kolstad \& Sani, 2010). As such, culture and social norms guide individuals' attitude towards ASD. If such beliefs are negative, it may cause exclusion of those with the disability. Given that Eastern cultures are considered to be collectivistic, social norms are particularly important to each individual (Ravindran \& Myers, 2011). In traditional Chinese culture, disability is viewed as a punishment for a sinful past life or the sinful past life of the person's parents (Holroyd, 2003; Huang Fried \& Hsu, 2009). This view may influence public attitudes as cultures helps the development of a value system, making the target notion more accessible and salient (Oyserman \& Spike, 2008). As such, parents are less likely to send their children to school and assume the responsibility for supporting and educating their children (Wang, Michaels \& Day, 2011). It should be noted, however, that prejudice also exists in Western culture. For example, much stigma exists around mental health disorders (e.g. Crisp, Gelder, Rix, Meltzer, \& Rowlands, 2000; Pinfold, Byrne, \& Toulmin, 2005; Thornicroft, Rose, Kassam, \& Sartorius, 2007). Despite this, Western individuals tend to show more positive attitudes towards people with disabilities than those in non-Western cultures (Westbrook, Legge, \& Pennay, 1993; Zaromatidis, Papadaki, \& Gilde, 1999).

Cultural differences in attitudes may be a result of individuals in Western culture having more opportunity to work with individuals with ASD (Barned et al., 2011; Segall, 2008). Indeed, Haimour and Obaidat (2013) found that teachers who had experience working with ASD students had a better understanding of the disability than teachers who had no previous experience of working with individuals with ASD. Others have reported similar results 
(Avramidis, Bayliss, \& Burden 2000; Corona, Christodulu, \& Rinaldi, 2017; McGregor \& Campbell, 2001) and even shown that teaching experience in general is related to more positive attitudes and knowledge towards inclusion (Avramidis, \& Kalyva, 2007; Brady \& Woolfson, 2008; Forlin, 1995). Teachers who have experience of ASD may be more willing to share their experience and offer support to others. Having experience of working with children with disabilities may increase knowledge of that disability. Teachers in China may therefore lack knowledge of ASD because they have less opportunities to work with and thus gain experience with children with the disability (Deng \& Manset, 2000).

Given the important role of knowledge to teachers' use of inclusive strategies for children with ASD, we need to understand what impacts upon this knowledge. The current study therefore had three main aims. The first aim was to investigate whether general teaching experience would influence teachers' knowledge of ASD. We predicted that teachers with more years teaching experience would have more knowledge of ASD (Avramidis, et al., 2000; Corona et al., 2017; Haimour \& Obaidat, 2013). The second aim was to investigate whether culture and experience teaching a child with ASD would impact on knowledge of ASD. It was hypothesised that teachers in the UK (Western culture) would report more experience of working with children with ASD that teachers in China (Barned et al., 2011; Segall, 2008). Finally, we expected that knowledge of ASD would be significantly different in teachers in the UK compared to teachers in China (Corona, et al., 2017; McGregor \& Campbell, 2001).

\section{Method}

\section{Design}

The current study was a between subjects design with the Independent variables being Culture (UK; China) and Experience of ASD (teachers who had experience of ASD; teachers 
who didn't have experience of ASD). The dependent variables were General teaching experience (1-5 years; more than 5 years); and Knowledge of ASD scores provided by the Knowledge about Childhood Autism among Health Workers (KCAHW; Bakare, Ebigbo, Agomoh \& Menkiti, 2008).

\section{Participants}

Following ethical approval from the universities where the research was carried out, consent was sought from all schools involved within both countries. Participant teachers were only invited to take part in the study and given consent forms if they were native to the countries (i.e. born in the UK or China). Public primary and secondary school teachers based in the UK or People's Republic of China were recruited. In total, data was collect from 45 UK schools and 37 Chinese schools. The teachers in the UK were recruited from schools in both England and Scotland ( $n=51 ; 46$ females and 5 males). For this group, age ranged 26-60 years from with a mean of 38.1 years (S.D. $=8.1)$. Over $15 \%$ had $1-5$ years' general teaching experience while $84.3 \%$ had over 5 years' general experience. $74.6 \%$ of the teachers taught in primary schools and $25.4 \%$ were secondary teachers. $80.5 \%$ of teachers in the UK reported having experience with children with ASD $(25.5 \%$ for more than 5 years, $27.5 \%$ for $2-5$ years, $27.5 \%$ for less than 2 years). Lastly, $62.8 \%$ of teachers reported having autism specific training. The teachers in China were recruited from schools in Shanghai, mainland China $(n=59 ; 53$ female and 6 male). For this group, age ranged from 22-50 years with a mean of 32.24 years (S.D. $=$ 8.33). Of these, $42.4 \%$ had $1-5$ years' general experience and $57.6 \%$ had over 5 years general teaching experience. $55.9 \%$ of the teachers taught in a primary school setting, whereas $44.1 \%$ taught secondary pupils. Over $28 \%$ of teachers in China reported having experience with children with ASD ( $0 \%$ had more than 5 years, 3.4\% had $2-5$ years, $25.4 \%$ had less than 2 years). $38.4 \%$ of the Chinese teachers reported to have autism specific training. 


\section{Procedure}

After ethical approval was obtained, questionnaire packs were distributed to head teachers from four schools (two in UK and two in China). As instructed by the ethics committee and in line with the British Psychological Society's ethical principles, each pack contained an information sheet, a consent form, the questionnaire and a debrief sheet and was emailed to schools. The questionnaire and the consent forms were translated into Chinese and were validated before sending to participants in China. Schools contacted the researcher when questionnaires were ready to be returned via email.

\section{Measures}

Demographic information.

Participants were asked to provide information regarding their gender, age, years of general teaching experience $(1=1-5$ years; $2=$ more than 5 years $)$, if they had experience of working with children with ASD $(1=$ yes $2=$ no $)$ and how many years' experience they had teaching children with ASD (i.e. $1=$ none $2=$ less than 2 years $3=2-5$ years $4=$ more than 5 years).

ASD knowledge Questionnaire.

The Knowledge about Childhood Autism among Health Workers (KCAHW; Bakare, Ebigbo, Agomoh \& Menkiti, 2008) questionnaire was used to assess knowledge of ASD among teachers. The scale comprises nineteen items with three response options of which, only one is correct. Example items are 'Autism is an auto-immune condition?' and 'Failure to develop peer relationship appropriate for developmental age?'. Correct responses receive a score of one while the remaining two options receive a score of zero. The minimum possible score is zero and the maximum score is 19 . The higher the score, the more knowledge of ASD the individual has. The reliability and validity of this measure has previously been 
reported as showing good overall internal consistency with Cronbach's alpha $=0.97$ (e.g. Bakare et al., 2008; Igwe, Ahanotu, Bakare, Achor \& Iawe, 2011) .

\section{Results}

In total, 128 teachers took part in the study, however, data from 18 participants was removed due to incomplete questionnaires. One hundred and ten teachers completed and returned the questionnaires. An independent T-test was carried out to examine if there were any differences of knowledge between primary and secondary school teachers, $\mathrm{t}(108)=.761$, $p=.448$, with primary school teachers $(\mathrm{M}=12.25, \mathrm{SD}=3.69)$ and secondary school teachers $(\mathrm{M}=11.67, \mathrm{SD}=4.20)$, showing no significant differences in ASD knowledge. Therefore primary and secondary results were collasped for the remaining analysis. Among the participants in the UK group, $80 \%$ of the teachers reported having experience with individuals with ASD. This meant they had experience of being in the same classroom with or personally had previously worked with children with ASD. In contrast, only over a quarter of the teachers $(28.8 \%)$ in the Chinese group had experiences with this population. A Chisquare test was performed to investigate if there was a significant association between general teaching experience ( $1-5$ years or more than 5 years) and culture $(p=.002)$, with the majority of teachers having more teaching experience in the UK. The socio-demographic characteristics of the participants are shown in Table 1.

\section{[Insert Table 1 here]}

Experience with ASD and Knowledge of ASD.

Analysis was carried out to examine if there were differences in knowledge of ASD between those teachers who had experience of teaching a child with ASD compared to those 
who did not. As indicated in Table 1, 56 teachers reported experiences of working with children with ASD while 54 teachers had no experience of this. As predicted, independent samples T-test showed that there was a significant difference between these two groups $(\mathrm{t}$ $(108)=6.99, \mathrm{p}<.001)$ with the experienced group demonstrating more knowledge $(\mathrm{M}=$ 14.12, $\mathrm{SD}=3.19)$ compared to those with no experience $(\mathrm{M}=9.78, \mathrm{SD}=3.34)$.

Culture, ASD Experience and Knowledge of ASD.

Next, we examined the role of both culture and experience by considering differences in knowledge of ASD between teachers in the UK and China ASD teaching expereince (i.e. time spent working with a child with ASD). A 2x4 between subjects ANOVA was carried out looking at the between factors culture (UK and China) and ASD teaching expereince (none, less than 2 years, 2-5 years and more than 5 years). There was no significant interaction between Culture and ASD teaching expereince on knowledge of ASD (F $(2,103)$ $=.83, \mathrm{p}=.431)($ see Figure 1$)$. There was no main effect of Culture $(\mathrm{F}(1,103)=.81, \mathrm{p}$ $=.372$ ) indicating that culture did not impact knowledge of ASD, however there was a significant main effect of ASD teaching expereince $(F(3,103)=4.72, p<.001)$. Post hoc Bonferroni analyses showed that this effect was driven by the differences between no ASD teaching expereince. There were significant differences for no ASD teaching experience (i.e. none, $\mathrm{M}=9.98, \mathrm{SD}=3.36$ ) compared to all the other levels of ASD teaching experience including those with less than 2 years $(\mathrm{M}=13.38, \mathrm{SD}=3.69) \mathrm{p}<.001,2-5$ years $(\mathrm{M}=13.81$, $\mathrm{SD}=3.712) \mathrm{p}<.001$, more than 5years $(\mathrm{M}=14.69, \mathrm{SD}=2,78) \mathrm{p}<.001$. There were no other significant differences between the different levels for ASD teaching expereince.

\section{[Insert Figure 1 here]}

Comparing knowledge of ASD between Chinese and UK teachers. 
Despite the non-significant effect of culture in the ANOVA carried out earlier, t-tests were carried out to test the final hypothesis which predicted that knowledge of ASD would be significantly different between UK and Chinese teachers. Results showed that there was a significant difference between the total knowledge of ASD score between teachers in China and the UK $(\mathrm{t}(108)=4.79, \mathrm{p}<.001)$. This suggests that $\mathrm{UK}$ based teachers $(\mathrm{M}=13.75 \mathrm{SD}=$ 3.42) had more knowledge of ASD than the China based teachers $(\mathrm{M}=10.47 \mathrm{SD}=3.69)$.

\section{Discussion}

This was the first study to examine the role of experience and culture on teachers' knowledge of ASD. The results showed that teachers who had experience working with children with ASD demonstrated a higher level of knowledge about the disorder. This finding was supported again in our examination of the role of ASD teaching experience. Those with no years' experience had significantly less knowledge of ASD than those with two or more years' experience. Finally, our results showed that UK teachers had significantly more knowledge of ASD than Chinese teachers.

\section{Experience}

Teachers who reported having experience teaching a child with an ASD scored significantly higher on the knowledge of ASD scale than those who reported no experience. This supports previous research which has found that teachers who have experience working with children with ASD have a better understanding of the disability than those who have no previous teaching experience with ASD individuals (i.e. Haimour and Obaidat, 2013; SanzCervera, Fernández-Andrés, Pastor-Cerezuela, \& Tárraga-Mínguez, 2017). This suggests the need of teacher education to provide student teachers with the opportunity to work with children with ASD in a supportive environment before they are qualified. This may, for example, involve teacher placements in special education settings during training. This would 
provide teachers with valuable experience in relation to working with those with ASD before they are required to lead his/her own classrooms.

We also found a significant effect of ASD teaching experience. On further examination and in line with the first hypothesis, this was found to be driven by the teachers who had no experience of working with a child with ASD. These teachers displayed significantly less knowledge than all the other categories of ASD teaching experience (i.e. less than 2 years, 2-5 years and more than 5 years). This supports the earlier finding of general teaching experience impacting knowledge of ASD scores, since those teachers lacking the concrete experience seem to have significantly lower knowledge of ASD. This is important given that experience (also referred to in the literature as contact and familiarity) has also been found to be a key factor in the formation of teacher's attitudes - another predictor of successful inclusion (Rodríguez, Saldana, \& Moreno, 2012; Scior, 2011). Future studies should examine the predictive power of experience across cultures on both attitudes towards inclusion and knowledge of ASD.

\section{Culture}

The study also examined the role of culture on knowledge of ASD. We found that teachers in the UK scored significantly higher on the KCAHW scores compared to teachers in China. This is in line with recent research such as Liu et al., (2016) who found that although teachers in China were highly motivated to learn more and gain greater skills in dealing with children with ASD, they lacked sufficient knowledge about the disorder. Further, $83 \%$ of our teachers in China sample provided incorrect answers to over half of the knowledge of ASD items. These significant differences in knowledge about ASD may be the result of inexperience or contact with children with ASD in China because caregivers assume more of the responsibility to educate their children at home due to limited educational 
resources (McCabe \& Tian 2002; Stratford \& Ng 2000; Wang, Michaels \& Day, 2011). Therefore teachers in China may have little knowledge of ASD, in part, due to the lack of opportunity to interact with individuals with the disability (Deng \& Manset, 2000). This seems to suggest that despite promoting inclusion, the People's Republic of China have to support and train both the families and professionals on the behaviours, language, challenging behaviours and educational interventions of ASD. Both families, caregivers and education professionals will need to network to highlight the perceived barriers within education and seek common solutions to tackle these barriers.

\section{Limitations}

The current study has extended our understanding of the role of culture and experience on knowledge of ASD. Such findings have important implications for teaching training and professional development. Despite this, we did not measure how such knowledge, culture or experience may impact upon teachers' beliefs or behaviour. Given that there is a relationship between teachers' attitudes and classroom behaviours (e.g. Wilson, et al., 2016), future research should consider the effects of culture and knowledges on attitudes towards inclusion and actual inclusive teaching practices used. Another limitation of is study is that it was difficult to ascertain whether the individuals who responded to the survey are representative of teachers in the UK and teachers in China. As such, there are limitations as to the extent to which the findings are generalizable.

\section{Conclusion}

This study was the first of its kind in examining the role of experience and culture on teachers' knowledge of ASD. The results showed that teachers who had experience working with children with ASD demonstrated a higher level of knowledge relating to the disorder. In addition experience of teaching children with ASD was important. Teachers who had no experience of ASD driving the significant differences in knowledge - indicating that 
experience is crucial for knowledge to be obtained. The current results also showed that teachers in the UK had significantly more knowledge of ASD than teachers in China. This study not only extends cross-cultural literature but also informs practice since it highlights the need for teachers to experience ASD if they are to gain sufficient knowledge.

\section{References}

Avramidis, E., Bayliss, P., \& Burden, R. (2000). A survey into mainstream teachers' attitudes towards the inclusion of children with special educational needs in the ordinary school in one Local Education Authority. Educational Psychology, 20, 191 - 211. 
Avramidis, E., \& Kalyva, E. (2007). The influence of teaching experience and professional development on Greek teachers' attitudes towards inclusion. European Journal of Special Needs Education 22, 367-389.

Avramidis, E., \& Norwich, B. (2002). Teachers' attitudes towards integration / inclusion: a review of the literature. European Journal of Special Needs Education, 17, 129-147.

Bakare, M. O., Ebigbo, P. O., Agomoh, A. O., \& Menkiti, N. C. (2008). Knowledge about childhood autism among health workers (KCAHW) questionnaire: description, reliability and internal consistency. Clinical Practice and Epidemiology in Mental Health, 4, 17.

Barnard, J., Broach, S., Potter, D. \& Prior, A. (2002). Autism in schools: Crisis or challenge? London: NAS

Barned, N. E., Knapp, N. F., \& Neuharth-Pritchett, S. (2011) Knowledge and attitudes of early childhood preservice teachers regarding the inclusion of children with autism spectrum disorder. Journal of Early Childhood Teacher Education, 32, 302-321

Brady, K., \& Woolfson, L. (2008). What factors influence teacher attributions for children's difficulties in learning? British Journal of Educational Psychology, 78, 527-544.

Brownell, M. T., Sinedelar, P. T., Kiely, M. T., \& Danielson, L. C. (2010). Special education teacher quality and preparation: Exposing foundations, constructing a new model. Exceptional Children, 76, 357-377.

Bunch, G., \& Valeo, A. (2004). Student attitudes towards peers with disabilities in inclusive and special education schools. Disability \& Society, 19, 61-76.

Burgess, A. F., \& Gutstein, S. E. (2007). Quality of life for people with autism: Raising the standard for evaluating successful outcomes. Child and Adolescent Mental Health, 12, 80-86. doi:10.1111/j.1475-3588.2006.00432.x

Carrington, S . \& Graham, L . (2001) Perceptions of school by two teenage 
boys with Asperger syndrome and their mothers: A qualitative study. Autism 5, 3748.

China Disabled Persons' Federation, Beijing University, \& National Bureau of Statistics of China. (2009). 2008 nian quanguo canjiren zhuangkuang ji xiaokang jincheng jiance baogao [Report on the status of persons with disabilities in China in year 2008]. Retrieved from http://www.sdpf.org.cn/2007special/zkjc/content/2008$\underline{12 / 11 / \text { content } 30199048 . h t m .}$

Crisp, A. H., Gelder, M. G., Rix, S., Meltzer, H. I., \& Rowlands, O. J. (2000). Stigmatisation of people with mental illnesses. British Journal of Psychiatry, 177, 4-7.

Corona, L. L., Christodulu, K. V., \& Rinaldi, M. L. (2017). Investigation of school professionals'self-efficacy for working with students with ASD: Impact of prior experience, knowledge, and training. Journal of Positive Behavior Interventions, 19, 90-101.

De Boer, A., Pijl, S. J., \& Minnaert, A. (2011). Regular primary schoolteachers' attitudes towards inclusive education: a review of the literature. International Journal of Inclusive Education, 15, 331-353.

Duncan, A. W., \& Grofer Klinger, L. (2010) Autism spectrum disorders: Building social skills in group, school, and community settings. Social Work with Groups, 33, 175 193.

Elsabbagh, M., Divan, G., Koh, Y.-J., Kim, Y. S., Kauchali, S., Marcín, C., Montiel-Nava, C., Patel, V., Paula, C. S., Wang, C., Yasamy, M. T., \& Fombonne, E. (2012), Global prevalence of autism and other pervasive developmental disorders. Autism Research, 5, 160-179. doi:10.1002/aur.239.

Farley, M. A., McMahon, W. M., Fombonne, E., Jenson, W. R., Miller, J., Gardner, M., Block, H., Pingree, C. B., Ritvo, E. R., Ritvo, R. A., \& Coon, H. (2009), Twenty-year 
outcome for individuals with autism and average or near-average cognitive abilities. Autism Research, 2, 109-118. doi:10.1002/aur.69.

Finch, K., Watson, R., MacGregor, C., \& Precise, N. (2013). Teacher needs for educating children with autism spectrum disorders in the general education classroom. The Journal of Special Education Apprenticeship, 2, 1-26.

Fombonne, E., Quirke, S., \& Hagen, A. (2011). Epidemiology of pervasive developmental disorders. In D.G. Amaral, G.Dawson, \& D.H. Geschwind (Eds.), Autism spectrum disorders (pp. 90-111). Oxford: Oxford University Press.

Ford, J. (2013). Educating students with learning disabilities in inclusive classrooms. Electronic Journal for Inclusive Education, 3, 1-20.

Forlin, C. (1995). Educators' beliefs about inclusive practices in Western Australia. British Journal of Special Education, 22, 179-185.

Holroyd E. E. (2003). Chinese cultural influences on parental caregiving obligations toward children with disabilities. Qualitative Health Research, 13, 4-19.

Huang Y. T., Fried J. H., \& Hsu T. H. (2009). Taiwanese mothers' attitude change toward individuals with disabilities. Journal of Social Work, Disability and Rehabilitation, 8, $82-94$.

Humphrey, N., \& Lewis, S. (2008). Make me normal: The views and experiences of pupils on the autistic spectrum in mainstream secondary schools. Autism, 12, 1362-3613.

Humphrey, N., \& Symes, W. (2013) Inclusive education for pupils with autistic spectrum disorders in secondary mainstream schools: teacher attitudes, experience and knowledge. International Journal of Inclusive Education, 17, 32-46

Leblanc, L., Richardson, W., \& Burns, K. A., (2009). Autism spectrum disorder and the inclusive classroom: effective training to enhance knowledge of ASD and evidencebased practices. Teacher Education and Special Education, 32, 166 - 179. 
Lindsay, G. (2007). Educational psychology and the effectiveness of inclusive education/mainstreaming. British Journal of Educational Psychology, 77, 1-24.

Liu Y, Li J, Zheng Q, Zaroff CM, Hall BJ, Li X, et al. (2016). Knowledge, attitudes, and perceptions of autism spectrum disorder in a stratified sampling of preschool teachers in China. BMC Psychiatry. 16: 142

McGregor, E., \& Campbell, E. (2001). The attitudes of teachers in Scotland to the integration of children with autism into mainstream schools. Autism, 5, 89- 208.

McCabe, H., \& Tian, H. P. (2002). Early intervention for children with autism in the People's Republic of China: A focus on parent training. The Journal of International Special Needs Education, 4, 39-43.

McCabe, H., Wu, S. X., \& Zhang, G. J. (2005). Experiences with autism in the People's Republic of China: Viewing social change through one family's story. Journal of International Special Needs Education, 8, 11-8.

National Foundation for Educational Research (2012). NFER Teacher Voice Omnibus February 2012 Survey: Pupil Behaviour (DFE Research Report 219). Retrieved from http://www.nfer.ac.uk/publications/91054/91054_home.cfm

Norbury, C. F., \& Sparks, A. (2013). Difference or disorder? Cultural issues in understanding neurodevelopmental disorders. Developmental Psychology, 49, 45-58.

Oyserman, D., \& Spike, L. W. S. (2008). Does culture influence what and how we think? effects of priming individualism and collectivism. Psychological Bulletin, 134, 311342.

Pang, Y., \& Richey, D. (2007). Preschool education in China and the United States: A personal perspective. Early Child Development and Care, 177, 1-13. 
Pinfold, V., Byrne, P., \& Toulmin, H. (2005). Challenging stigma and discrimination in communities: A focus group study identifying UK mental health service users' main campaign priorities. International Journal of Social Psychiatry, 51, 128-138.

Revicki, D. A., Osoba, D., Fairclough, D., Barofsky, I., Berzon, R., Leidy, N. K., \& Rothman, M. (2000). Recommendations on health-related quality of life research to support labeling and promotional claims in the United States. Quality of Life Research, 9, 887-900.

Rodríguez, I. R., Saldana, D., \& Moreno, F. J. (2012). Support, inclusion, and special education teachers' attitudes toward the education of students with autism spectrum disorders. Autism Research and Treatment, 2012.

Rowley, E., Chandler, S., Baird, G., Simonoff, E., Pickles, A., Loucas, T., \& Charman, T. (2012). The experience of friendship, victimization and bullying in children with an autism spectrum disorder: Associations with child characteristics and school placement. Research in Autism Spectrum Disorders, 6, 1126-1134.

Sanz-Cervera, P., Fernández-Andrés, M. I., Pastor-Cerezuela, G., \& Tárraga-Mínguez, R. (2017). Pre-service teachers' knowledge, misconceptions and gaps about autism spectrum disorder. Teacher Education and Special Education, 0888406417700963.

Scior, K. (2011). Public awareness, attitudes and beliefs regarding intellectual disability: A systematic review. Research in Developmental Disabilities, 32, 2164-2182.

Segall, M. (2008). Inclusion of students with autism spectrum disorder: Educator experience, knowledge, and attitudes. Unpublished master's thesis, University of Georgia, Athens, GA.

Simpson, R. L., Boer-Ott, S. R., and Smith-Myles, B. (2003) Inclusion of learners with autism spectrum disorders in general education settings. Topics in Language Disorders, 23, (2), 116-133. 
Smith, L., E., Maenner, M. J., \& Seltzer, M. M. (2012). Developmental trajectories in adolescents and adults with autism: The case of daily living skills. Journal of the American Academy of Child \& Adolescent Psychiatry, 51, 622-631. https://doi.org/10.1016/j.jaac.2012.03.001

Stratford, B., \& Ng, H. (2000). People with disabilities in China: Changing outlook-new solutions-growing problems. International Journal of Disability, Development and Education, 47, 7-14.

Subban, P., \& Sharma, U. (2005). Understanding educator attitudes toward the implementation of inclusive education. Disability Studies Quarterly, 25.

Thornicroft, G., Rose, D., Kassam, A., \& Sartorius, N. (2007). Stigma: ignorance, prejudice or discrimination? British Journal of Psychiatry, 190, 192-193.

UNESCO (1994). The UNESCO Salamanca Statement and framework for action on special needs education. Paris: UNESCO.

UNESCO. (2001). The open file on inclusive education. Paris: UNESCO

UNESCO. (2005). Guidelines for inclusion: Ensuring access to education for all, Paris, France: United Nations Educational, Scientific and Cultural Organization. United Nations. (1989). United Nations convention on the rights of the child. G. A. Res 44/25, Annex. 44 U.N.GAOR Supp (No. 49) at 167, U.N. Doc. A/44/49.

United Nations. (2006).Convention on the rights of persons with disabilities. New York: United Nations.

Wang, P., Michaels, C. A., \& Day, M. S. (2011). Stresses and coping strategies of Chinese families with children with autism and other developmental disabilities. Journal of Autism and Developmental Disorders, 41, 783-795.

Westbrook, T. M. Legge, V., \& Pennay, M. (1993). Attitudes towards disabilities in multicultural society. Social Science and Medicine, 36, 615-623. 
Wilson, C., Woolfson, L., Durkin, K., \& Elliott, M. A. (2016). The impact of social cognitive and personality factors on teachers' reported inclusive behaviour. British Journal of Educational Psychology, 86, 461-480. DOI:10.1111/bjep.12118.

Wong, C., Odom, S. L., Hume, K. A., Cox, A. W., Fettig, A., Kucharcyk, S., Brock, M. E., Plavnick, J. B., Fleury, V. P., \& Schultz, T. R. (2015). Evidence-based practices for children, youth, and young adults with autism spectrum disorder: A comprehensive review. Journal of Autism and Developmental Disorders, 45, 1951-1966.

Zaromatidis, K., Papadaki, A., \& Gilde, A. (1999). A cross-cultural comparison of attitudes toward persons with disabilities: Greeks and Greek-Americans. Psychological Reports, 84, 1189-1196. 